\title{
19. TECTONIC, VOLCANIC, AND SEDIMENTOLOGIC SIGNIFICANCE OF VOLCANIC GLASSES FROM SITE 450 IN THE EASTERN PARECE VELA BASIN, DEEP SEA DRILLING PROJECT LEG 59
}

\author{
Kelvin S. Rodolfo and Russell J. Warner, Department of Geological Sciences, University of Illinois at \\ Chicago Circle, Chicago, Illinois
}

\section{INTRODUCTION}

Site 450 is located in the Parece Vela Basin $76 \mathrm{~km}$ east of the IPOD Trough, a portion of the presumed former spreading center of the basin. Drilled in 4707 meters of water, the hole yielded 265.7 meters of volcaniclastic sediments and sedimentary rocks beneath the surficial 67.3-meter layer of pelagic clay.

As at all other Leg 59 sites, pumice fragments and volcaniclastic deposits were sampled in the hope that shore-based analyses of these materials would provide (1) clues concerning the tectonic and volcanic histories of the site and (2) data bearing upon the complex processes of arc-sundering and back-arc spreading. The volcanic-glass sampling program proved disappointing at the other sites. Holes 448 and 451 , drilled in the Palau-Kyushu and West Mariana ridges, respectively, yielded great abundances of volcanic glass; unfortunately, volcaniclastic depositional rates had been so great that the sediments had all accumulated over indeterminant short spans of time. Depositional rates and time horizons could not be determined precisely for either of these ridge sites because neither sedimentary column contains fossils from more than a single clearly defined biostratigraphic zone. At Site 449 , on the other hand, volcaniclastic debris occurs in a sedimentary column that represents 4 or $5 \mathrm{~m} . \mathrm{y}$. of deposits; however, these glasses are only a minor component of the clays and oozes and were not sampled in sufficient volume to be studied according to the methods we used for the glasses of Site 450 . It may well be fruitful to analyze the Site 449 glasses in the future.

Site 450 is situated far enough from volcaniclastic arc provenance so that the depositional rates were slow. Good biostratigraphic control indicates that volcanic debris accumulated during at least 3 m.y. of the earliest middle Miocene (Fig. 1). Volcanic glasses were sampled at 21 horizons in Hole 450 . The uppermost 3 samples are from ashy horizons in the pelagic clay unit overlying the main volcaniclastic unit from which the other 18 samples were taken. At the University of Illinois in Chicago we examined these materials optically, paying particular attention to refractive indices (RI) as a good first approximation of silica content; the samples throw some interesting light on the tectonic, volcanic, and sedimentologic history of the Parece Vela Basin and West Mariana Ridge and indicate promising avenues for future work.

\section{LABORATORY ANALYSIS}

Subsamples of 1- to 2- $\mathrm{cm}^{3}$ volumes were washed free of their fin fractions by immersion in $90 \mathrm{ml}$ of distilled water, ultrasonic disag. gregation, and decantation. This treatment was repeated until the supernatant water was clear of fines. The samples from the ashy horizons in the pelagic clay unit contained little coarse material, and additional 1- to $2-\mathrm{cm}^{3}$ volumes had to be processed to provide sufficient glass for analysis.

Small quantities of the washed sample were mounted on glass slides in an oil of known refractive index. Under transmitted light, a standard set of microscopic observations was made: the respective percentages of lithic, crystal, and glass grains; the mean grain sizes of the glass and of the combined lithic and crystal components; and the respective percentages of the colored and colorless glass fragments. These values are plotted in Figure 1 and presented in Table 1.

In the determinations of refractive indices, the only glass fragments analyzed were those barren of crystalline inclusions and those that were completely isotropic. Colored fragments invariably displayed a higher refractive index than did colorless shards. To determine the range of index for each color population, between 15 and 20 fragments of each color were examined. If fewer than $90 \%$ of the fragments in a color population had indices less than that of the index oil, another mount was made in an oil with an index 0.004 higher than that of the first oil. This process was repeated until the upper limit of all color populations had been determined. The lower limits of the refractive indices of each population were determined in similar fashion. In order to avoid observer bias and premature interpretation, we conducted analyses in random sequence on the entire suite of samples.

\section{RESULTS}

In all, 26 samples were processed. One contained insufficient volcaniclastic material for analysis. The top two samples, from the pelagic clay layer (Sub-unit 1a), and the bottom two samples (Sub-unit $2 \mathrm{~b}$ ) were barren of glass but contained substantial crystal and lithic components.

The lithic component in these samples ranges erratically between a few per cent and $90 \%$, although typical values are 10 to $40 \%$. Crystal content is less erratic, normally ranging between 10 and $30 \%$, with most low values occurring at mid-depths in the hole.

Significant differences in the glass data occur between those samples taken from 180-meter depths and above those from 190 meters and below. Thus, it is convenient to discuss the data in terms of the arbitrarily chosen 185-meter depth horizon (marked as a line of open circles in Fig. 1). Below this depth all samples but one have glass components ranging from 40 to $70 \%$ and averaging about $60 \%$. The anomalous sample, at 265 meters, contains only $5 \%$ glass and is a lithic siltstone. Above 185 meters, total glass content ranges erratically from 15 to $80 \%$, averaging about $50 \%$. Values exhibit a 


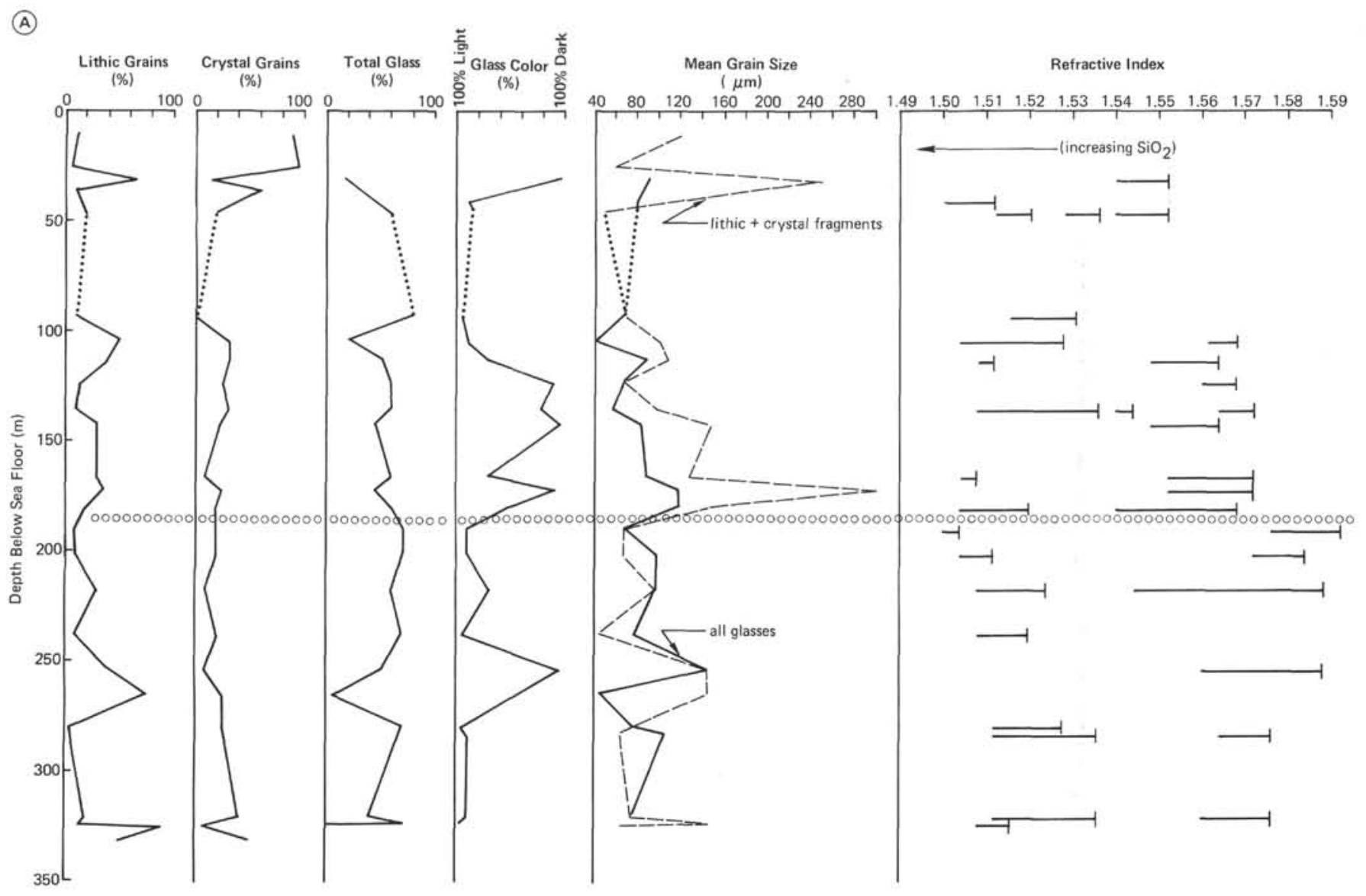

Figure 1. Volcaniclastic glass data in a biostratigraphic and volcano-tectonic context for Site 450 . A. The different glass data are summarized. B. The sedimentologic interpretations of these data are presented in a framework illustrating biostratigraphy and depositional rates. (The line of open circles marks a significant horizon at 185 meters below the sea floor, separating higher and lower groups of rocks differing in the trends of their glass properties.)

general upward-decreasing trend from the 185-meter horizon to the 104-meter depth; however, the maximum glass content occurs at 93 meters. Upward from this depth the glass contents again decrease.

The glass fragments below the 185-meter depth are predominantly colorless, except for a horizon at 254 meters of dark-colored, well-sorted fine sand, composed of $95 \%$ dark glass. With this exception, the glasses below 185 meters are typically 70 to $95 \%$ colorless, averaging $90 \%$.

Between 123 and 185 meters, the relative abundances of colored and colorless glasses are significantly different. Colored glass in this interval ranges between 30 and $95 \%$ of total glass contents, averaging about $70 \%$. Above the 123-meter horizon the abundance of dark glass decreases again-to $5 \%$ at a depth of 93 meters. The glass from one sample taken from a coarse bed within the pelagic clay at 31 meters below the mudline (Sub-unit $1 \mathrm{~b}$ ) was $90 \%$ colored; this sample proved to be a coarse lithic sand.

Below the 185-meter horizon the grain sizes of glass fragments tend to be slightly greater than or equal to the sizes of lithic and crystal fragments. Mean sizes range from 60 to $150 \mu \mathrm{m}$, averaging about $100 \mu \mathrm{m}$ for glasses and $90 \mu \mathrm{m}$ for the lithic-crystal component. Above 185 meters, lithic and crystal fragments typically are distinctly coarser than the glass shards, ranging between 50 and $280 \mu \mathrm{m}$ in mean size and averaging about $125 \mu \mathrm{m}$, compared to the glass range of 40 to $120 \mu \mathrm{m}$, with average size of $85 \mu \mathrm{m}$. This size disparity is especially pronounced in the 92 meters of the column above 185 meters. It is also noteworthy that a fairly good correlation exists between the mean lithic-crystal grain size and the relative abundance of colored glass.

Our most interesting results are the refractive-index data for the glasses. Of the 21 samples containing enough glass to analyze, 11 had at least two glass populations distinguished by refractive index as well as color; of these, 2 samples from above the 185-meter horizon had three such populations. In all cases, these populations occur in three well-defined groups: two groups with indices higher than 1.540 and one group with indices lower than 1.536. (The value of 1.540 is given by Keller and others [1978] as the lowest index for basaltic glasses.)

Again, the 185-meter depth horizon is significant, for it divides the colored, high-index basaltic glasses into separate lower and upper groups. Below 185 meters, the glasses have two clearly defined populations that change systematically with depth. The colorless glass, compris- 


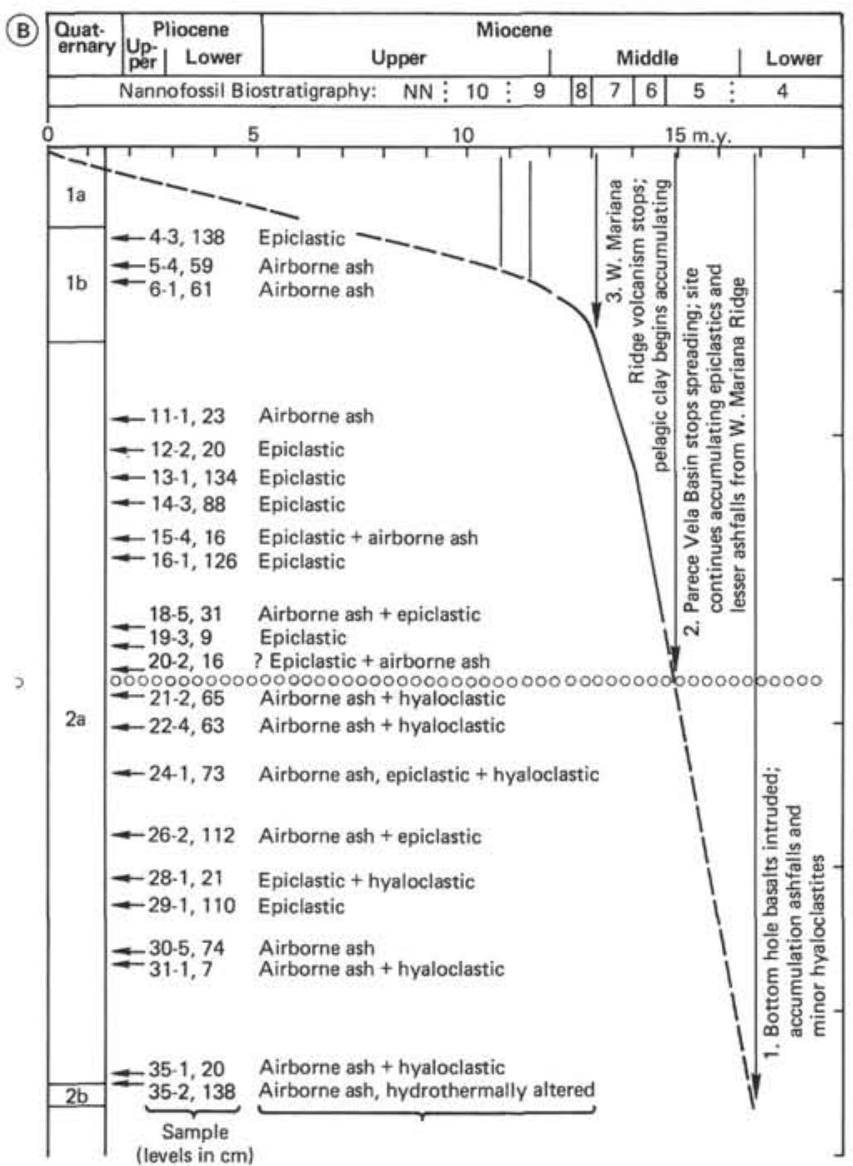

Figure 1. (Continued).

ing an average $90 \%$ of total glass in all but one sample, shows an upward decrease in refractive index. (The only exception to this trend is the lowermost sample, taken from the hydrothermally altered Sub-unit $2 \mathrm{~b}$.) The dark glass in these samples, averaging only about $10 \%$ of total glass, exhibits a contrary trend, becoming higher in refractive index (more basaltic) from the lowest occurrence up to 190 meters. The only sample in which dark glass predominates, at 254 meters, also falls within this trend but displays a wider index range.

Above 185 meters, the abrupt increase in the coloredglass component noted earlier is matched by a distinct shift in refractive indices toward lower values, and the indices decrease up the sedimentary column. The light glasses above 185 meters, exhibit no clearly defined trend with depth in the hole.

\section{DISCUSSION}

As noted in the Introduction (to this volume), the processes of fragmentation and transport that produced the Leg 59 volcaniclastic sediments are exceedingly varied and complex. The material may include debris supplied (1) more or less directly by local and distant subaerial and submarine eruptions, (2) by turbidity currents and other density flows penecontemporaneous with frontal-arc volcanism and tectonism, and (3) by epiclastic turbidity currents and submarine slumps from the frontal arcs. Other fragmentation and transport mechanisms, as yet unrecognized, may also have contributed volcaniclastic materials. Additional complications may have been introduced by reworking, because gravitational movements are facilitated by steep topography and by the seismicity that accompanies continuing frontal-arc volcanism and tectonism.

Notwithstanding these complications, the foregoing data permit tentative interpretations of the genesis of the materials from Site 450 and provide clues regarding the tectonic and volcanic histories of the Parece Vela Basin and West Mariana Ridge. In addition to the sysematic data presented in Figure 1, records were kept of grain sorting and rounding. All these parameters are used as the bases for interpreting a sedimentary genesis presented in Table 2. These interpretations and those given on the right side of Figure 1 must be regarded as hypotheses that remain to be tested by further research utilizing more sophisticated approaches, including electron probe and X-ray analyses, electron microscopy, and Fourier analysis of grain shapes.

We tentatively recognize three basic sedimentologic modes, two or all three of which may be represented in the same sample, as Figure 1 shows: (1) subaerial explosion products transported to the site in the atmosphere-these are composed primarily of glass shards with low refractive indices (i.e., high silica) that are finegrained, well sorted, and angular; (2) fragmental basaltic glasses with the highest refractive indices (lowest silica) encountered during the study, produced by submarine eruptions as hyaloclastites or as products of deep-sea reworking of Parece Vela basalts, comprising only minor fractions of the total sediment and occurring as fine to intermediate-sized, fairly well-sorted angular clasts; and (3) epiclastic, poorly sorted, coarse and rounded lithic clasts and glass fragments of variable color and refractive index (the basaltic glasses with refractive indices generally lower than those of the hyaloclastites). The explosion products occur throughout the sediment column but dominate below 185 meters. Hyaloclastites are restricted to the column below 185 meters, and epiclastics occur both above and below this point, being the principal material above 185 meters.

Inasmuch as we place great significance upon the refractive-index data, it is appropriate that we discuss their use and validity for estimating silica contents. The inverse correlation between silica content and refractive index has been known and used for a long time (e.g., cf. George, 1924; Huber and Reinhart, 1966). Magma differentiation of basalts involves silica enrichment, which results in reduced indices; thus, maximal indices represent the least differentiated magma and therefore the closest to primary magma type. Differentiation of andesitic magmas, on the other hand, should not change refractive indices because the crystallizing minerals have the same silica content as the liquid (Marsh, 1979). Thus, the observed changes in refractive indices through time must result from diagenetic changes in the glasses or from changes in magma type at the source.

Palagonitization or hydration of glasses is effected by removal of major elements, especially iron and magnesium in basaltic glasses, and their replacement by 
Table 1. Summary of analytic results for Hole 450 .

\begin{tabular}{|c|c|c|c|c|c|c|c|c|c|c|c|}
\hline \multirow{2}{*}{$\begin{array}{c}\text { Sample } \\
\text { (core-section, } \\
\text { level in cm) }\end{array}$} & \multicolumn{5}{|c|}{ Modal Analysis (\%) } & \multicolumn{3}{|c|}{ Size Distribution } & \multicolumn{3}{|c|}{ Glass Refractive Index } \\
\hline & Lithic & Crystal & Glass- & Colored & Clear & $\begin{array}{l}\text { Total } \\
\text { Range }\end{array}$ & $\begin{array}{c}\text { Mean } \\
\text { Lithic-Crystal }\end{array}$ & $\begin{array}{l}\text { Mean } \\
\text { Glass }\end{array}$ & $\begin{array}{l}\text { Clear } \\
\text { Glass }\end{array}$ & $\begin{array}{l}\text { Light-Color } \\
\text { Glass }\end{array}$ & $\begin{array}{l}\text { Dark-Color } \\
\text { Glass }\end{array}$ \\
\hline $2-3,9$ & 10 & 90 & 0 & - & - & $100-150$ & 120 & - & - & - & - \\
\hline $3-6,17$ & 5 & 95 & 0 & - & - & $40-90$ & 60 & - & - & - & - \\
\hline $4-3,138$ & 65 & 15 & 20 & 90 & 10 & $1-600$ & 250 & 90 & - & - & $1.540-1.552$ \\
\hline $5-4,59$ & 10 & 60 & 30 & 10 & 90 & $9-120$ & 100 & 80 & $1.500-1.512$ & - & - \\
\hline $6-1,61$ & 20 & 20 & 60 & 15 & 85 & $10-100$ & 50 & 80 & $1.512-1.520$ & $1.528-1.536$ & $1.540-1.552$ \\
\hline $11-1,23$ & 80 & 10 & 10 & 5 & 95 & $30-100$ & 70 & 70 & $1.516-1.532$ & - & - \\
\hline $12-2,20$ & 50 & 30 & 20 & 10 & 90 & $10-150$ & 100 & 40 & $1.504-1.528$ & - & $1.564-1.568$ \\
\hline $13-1,134$ & 20 & 30 & 50 & 30 & 70 & - & 115 & 90 & $1.508-1.512$ & - & $1.548-1.564$ \\
\hline $14-3,88$ & 15 & 25 & 60 & 90 & 10 & $20-150$ & 70 & 70 & - & - & $1.560-1.568$ \\
\hline $15-4,16$ & 10 & 30 & 60 & 80 & 20 & $50-200$ & 100 & 60 & $1.508-1.532$ & $1.540-1.544$ & $1.564-1.572$ \\
\hline $16-1,126$ & 30 & 25 & 45 & 95 & 5 & $50-200$ & 150 & 85 & - & - & $1.548-1.564$ \\
\hline $18-5,31$ & 30 & 10 & 60 & 30 & 70 & $50-250$ & 130 & 90 & $1.504-1.508$ & - & $1.552-1.572$ \\
\hline $19-3,9$ & 35 & 25 & 45 & 90 & 10 & $30-300$ & 280 & 120 & - & - & $1.552-1.572$ \\
\hline $20-2,16$ & 20 & 20 & 60 & 50 & 50 & $50-300$ & 150 & 120 & $1.504-1.520$ & - & $1.540-1.568$ \\
\hline $21-1,65$ & 10 & 20 & 70 & 10 & 90 & $20-100$ & 70 & 70 & $1.500-1.504$ & - & $1.576-1.592$ \\
\hline $22-4,63$ & 10 & 20 & 70 & 10 & 90 & $10-150$ & 70 & 100 & $1.504-1.512$ & - & $1.572-1.584$ \\
\hline $24-1,73$ & 30 & 10 & 60 & 30 & 70 & $50-250$ & 100 & 100 & $1.508-1.524$ & - & $1.544-1.588$ \\
\hline $26-2,112$ & 10 & 20 & 70 & 5 & 95 & $30-130$ & 50 & 80 & $1.508-1.520$ & - & - \\
\hline $28-1,21$ & 40 & 10 & 50 & 95 & 5 & $50-220$ & 150 & 150 & - & - & $1.560-1.588$ \\
\hline $29-1,110$ & 70 & 25 & 5 & - & - & $20-200$ & 150 & - & - & - & - \\
\hline $30-5,74$ & 5 & 25 & 70 & 5 & 95 & $50-90$ & 80 & 80 & $1.512-1.528$ & - & - \\
\hline $31-1,7$ & 20 & 10 & 70 & 10 & 90 & $20-300$ & 70 & 110 & $1.512-1.536$ & - & $1.564-1.576$ \\
\hline $35-1,20$ & 20 & 40 & 40 & 10 & 90 & $20-100$ & 80 & 80 & $1.512-1.536$ & - & $1.560-1.576$ \\
\hline $35-2,138$ & 15 & 15 & 70 & 5 & 95 & $50-200$ & 150 & 150 & $1.508-1.516$ & - & - \\
\hline $35-3,61$ & 90 & 10 & 0 & - & - & $20-150$ & 70 & - & - & - & - \\
\hline $36-1,78$ & 50 & 50 & 0 & - & - & $50-150$ & 60 & - & - & - & - \\
\hline
\end{tabular}

Table 2. Bases for the tentative genetic classification of Site 450 volcaniclastics.

\begin{tabular}{|c|c|c|c|}
\hline Characteristic & $\begin{array}{l}\text { Subaerial Explosive, } \\
\text { Probably Airborne }\end{array}$ & $\begin{array}{c}\text { Hyaloclastic, or Otherwise Derived } \\
\text { from Parece Vela Back-Arc } \\
\text { Basaltic Volcanism }\end{array}$ & Epiclastic and Reworked \\
\hline Lithic Content & Low & Low to intermediate & High \\
\hline Crystal Content & Low to intermediate & Low & Intermediate \\
\hline Glass Content & $\begin{array}{l}\text { High, predominantly colorless, with low } \\
\text { refractive index (RI), presumably with } \\
\text { high } \mathrm{SiO}_{2} \text { and low } \mathrm{Fe}, \mathrm{Ti} \text { content. RIs } \\
\text { decrease upward to } 185 \mathrm{~m} \text {, show no } \\
\text { trend above that depth. }\end{array}$ & $\begin{array}{l}\text { Minor component of the total glass con- } \\
\text { tent; dark, high } \mathrm{RI} \text {, presumably low } \\
\mathrm{SiO}_{2} \text { and high } \mathrm{Fe} \text {, } \mathrm{Ti} \text { content; RIs below } \\
185 \mathrm{~m} \text { increase up to that depth. }\end{array}$ & $\begin{array}{l}\text { Variable contents, variable colors; the } \\
\text { dark glasses have lower RI than hyalo- } \\
\text { clastites, these RIs decreasing up-hole } \\
\text { from } 185 \mathrm{~m} \text {. }\end{array}$ \\
\hline Grain Size & Fine & Fine to intermediate & Coarse, especially the lithic clasts \\
\hline Sorting & Good & Fair & Poor \\
\hline Clast Rounding & Angular & Angular to subangular & Subangular to rounded \\
\hline
\end{tabular}

water (Furnes, 1975). Hydration would cause a reduction in refractive index; thus, maximal index values should represent the least diagenetically affected glasses. We therefore conclude that both magma differentiation and diagenesis act to reduce refractive index, and the highest indices occur in those glasses that are most primary-and least altered by diagenesis. Consequently, we place more reliance on the maximal indices of the basic glass types.

Up to the 185 -meter horizon, the index maxima of the dark glasses increase through time. The trend could be interpreted as a diagenetic effect: the deepest and oldest glasses, having undergone the longest period of hydration, could be expected to possess the lowest refractive indices. This interpretation is contradicted strongly by the colorless glasses in the same samples, which become more silicic up-hole. We conclude instead that the trends in refractive index represent genuine changes in magma type at the source.

The increase in basaltic character of the dark glasses over time below the 185 -meter horizon has major implications for petrogenesis during the arc-sundering process. Initial sundering occurs in the arc itself; thus, the primary phase of back-arc extrusives can be expected to be relatively silica-rich, because of the proximity of andesitic arc volcanism as well as contamination by andesitic rocks assimilated during sundering. As the back-arc basin continues to spread, the spreading center 
becomes farther removed from andesitic provenance and thus should become more basaltic through time.

The upward and temporal decrease in refractive index of the colorless glasses in the column before 185 meters raises an interesting question concerning the discreteness of the sources for andesitic-arc and basaltic back-arc basin magmas. Refractive-index maxima for the clear glasses indicate that the primary magma was a basaltic andesite. As back-arc spreading separated the extrusive centers more widely, arc volcanism became progressively more andesitic. This implies that strong interplay between the andesites and basalts existed initially and that through time the sources must have become more discrete. If we extrapolate farther back in time, past the period of emplacement of the Site 450 bottom-hole basalts, do all the volcanics converge at a single magma type? If so, what was this initial magma type? Some light may be shed on this question by analyzing the volcanic glasses from Site 449 , which are older and for which good biostratigraphic control exists.

Above the 185-meter horizon the glasses exhibit distinctly different maximal refractive-index trends than do those in the underlying column. The silica content of the dark glasses decreases sharply above that boundary and continues to decrease upward. It is not clear what this trend in the predominantly epiclastic glasses means, although the break at 185 meters nonetheless serves as an important geochemical discontinuity. The colorless glasses above the 185 -meter horizon show no distinct trends, and the ranges in refractive indices vary widely, as might be expected in epiclastic deposits derived from an arc of varied petrology. It is interesting that refractive-index maxima in the colorless glasses indicate a basaltic andesite source. Could these airborne ashes represent initiation of the latest episode of arc sundering that created the Mariana Trough? Poor recovery in the 48- to 94-meter interval precluded investigation of this speculation.

The biostratigraphic record indicates an age of 15 m.y. for the 185 -meter horizon. We interpret the changes across this boundary, particularly the termination of the "hyaloclastic" basalt glasses, as representing the end of Parece Vela Basin spreading. This interpretation fits well with the time of spreading estimated from Hole 449
Hole 449 data (see Sartori and Tomadin, this volume). Prior to 15 m.y. ago, Site 450 was below the CCD, as seen by the absence of foraminifers. The changes we observed in the glasses upward from 185 meters are matched closely by the first appearances of foraminifers in the sediments, indicating that the sea floor underwent uplift to the CCD at this time. It is reasonable to expect a degree of uplift to accompany the cessation of backarc spreading. The uplift is also noted at Site 449 in the Parece Vela Basin west of the IPOD Trough.

\section{SUMMARY}

The basalts at the termination of Hole 450 were intruded in the latest early Miocene or earliest middle Miocene. Prior to this event, volcaniclastic sediments were already accumulating at the site. The record of the drilled column up to the 185-meter depth is one of accumulation of airborne andesitic tephra, augmented by minor but ubiquitous amounts of increasingly basaltic glass fragments of hyaloclastic origin or produced by deep-sea reworking of Parece Vela Basin basalts. The glass data indicate that the Parece Vela Basin ceased spreading about 15 m.y. ago. Subsequently, epiclastic events and lesser subaerial eruptions on the West Mariana Ridge continued to supply volcaniclastic debris to the site until about $12 \mathrm{~m}$.y. ago, when West Mariana Ridge volcanism ceased and pelagic clays began to accumulate until the present day. Ash beds in the pelagic clay may represent renewed arc volcanism associated with initiation of the sundering that has produced the Mariana Trough. This hypothetical history and its details remain to be evaluated through further research.

\section{REFERENCES}

Furnes, H., 1975. Experimental palagonitization of basaltic glasses of varied composition. Contrib. Mineral. Petrol., 50:105-113.

George, W. O., 1924. Relation of the physical properties of the natural glasses to their chemical composition. J. Geol., 32:353-372.

Huber, N. K., and Reinhart, C. D., 1966. Some relationships between refractive index of fused glass beads and the affinity of volcanic rock suites. Bull. Geol. Soc. Am., 77:101-110.

Keller, J., Ryan, W. B. F., Ninkovich, D., et al., 1978. Explosive volcanic activity in the Mediterranean over the past 200,000 years as recorded in deep-sea sediments. Bull. Geol. Soc. Am., 89: 591-604.

Marsh, B. D., 1979. Island-arc volcanism. Am. Scientist, 67:161-172. 